\title{
Eritrograma, estresse oxidativo e interação mineral em cordeiros naturalmente infectados por parasitas gastrintestinais suplementados com diferentes formas de ferro oral
}

\section{Erythrogram, oxidative stress and mineral interaction in naturally infected lambs supplemented with different forms of oral iron}

\author{
Ricardo Xavier Rocha ${ }^{*}$; Emmanuel Veiga Camargo ${ }^{2}$; Diego Zeni²; Paula Rocha \\ Sampaio Nicolodi ${ }^{3}$; Marta Lizandra Rêgo Leal'; ${ }^{4}$ Marcelo Silva Cecim ${ }^{4}$
}

\section{Resumo}

\begin{abstract}
O presente estudo teve por objetivo avaliar o perfil oxidativo, eritrograma e interação mineral em cordeiros com anemia verminótica suplementados com diferentes formas de ferro oral. Foram utilizados 27 cordeiros com idade entre 6 e 8 meses naturalmente infectados por Haemonchus contortus, apresentando volume globular entre 16 e 18\%. Os animais foram divididos em três grupos; Grupo controle (GC) n=9, Grupo Sulfato ferroso (G2) n=9 e Grupo Sulfato férrico (G3) n=9. Os animais do G2 receberam via oral, diariamente 1 grama de sulfato ferroso $\left(\mathrm{Fe}^{+2}\right)$, equivalente a 200 miligramas de ferro, os animais do $\mathrm{G} 3$ receberam 1 grama de sulfato férrico $\left(\mathrm{Fe}^{+3}\right)$ via oral, diariamente, equivalente a 200 miligramas de ferro, os animais do GC não receberam tratamento. As coletas foram realizadas nos dias $0,7,14,21$ e 28 do experimento, e durante quatro dias dois animais de cada grupo foram mantidos em gaiolas metabólicas para mensuração da excreção fecal de minerais. Não houve diferença entre os grupos nos valores de ferro sérico e parâmetros de eritrócitos do sangue. Os valores de cobre e zinco sérico foram inferiores nos G2 e G3 nos dias 21 e 28 do experimento, enquanto que a excreção fecal de cobre, ferro e zinco foram superiores nesses mesmos grupos. Os teores da superoxido desmutase (SOD) foram inferiores nos G2 e G3 no dia 28 enquanto que os teores dos grupos tióis protéicos (NPTH) foram menores nos G2 e G3 nos dias 21 e 28. Os valores de espécies reativas ao ácido tio-barbitúrico (TBARS) foram maiores no dia 28 nos G2 e G3. A suplementação de 200mg de ferro, independente da sua forma, ferrosa ou férrica, não aumenta a resposta eritrocitária em cordeiros com anemia verminótica. Esses compostos possuem ação antagonista sobre cobre e zinco, diminuindo as concentrações séricas desses minerais e aumentando excreção fecal dos mesmos. Em decorrência da diminuição das concentrações séricas de cobre e zinco houve uma diminuição da atividade da superóxido dismutase causando estresse oxidativo.
\end{abstract}

Palavras-chave: Ovinos, suplementação, minerais, estresse oxidativo

\begin{abstract}
The present study aimed to assess the oxidative profile, erythrogram and mineral interaction in lambs with anemia due to worm infection supplemented with different forms of oral iron. It was used 27 lambs, 6 to 8 month old, naturally infected by Haemonchus contortus, which showed packed cell volume between 16 and $18 \%$. The animals were divided in three groups: Control Group (GC) $n=9$, Ferrous Sulphate Group (G2) n=9 and Ferric Sulphate Group (G3) n=9. The animals of G2 received $1 \mathrm{~g}$
\end{abstract}

1 Prof. da Universidade do Oeste de Santa Catarina, Xanxerê, SC. E-mail: ricardo.rocha@unoesc.edu.br

2 Profs. da Universidade Federal do Pampa, Alegrete, RS. E-mail: manecovcvet@yahoo.com.br; diegostreitzeni@yahoo.com.br

Prof ${ }^{\mathrm{a}}$. da Universidade de Cruz Alta, Cruz Alta, RS. E-mail: pveloso@unicruz.edu.br

4 Profs.da Universidade Federal de Santa Maria, Santa Maria, RS. E-mail: martali@usp.br; mcecim@ufsm.br

Autor para correspondência 
of ferrous sulphate $\left(\mathrm{Fe}^{+2}\right)$ orally daily, equivalent to 200 milligram of iron, the animals of $\mathrm{G} 3$ received 1 $\mathrm{g}$ of ferric sulphate $\left(\mathrm{Fe}^{+3}\right)$ orally daily, or equivalent to 200 milligram of iron, whereas the $\mathrm{GC}$ received no treatment. The samples were taked on day $0,7,14,21$ and 28 of the experiment, and during four days two animals of each group were kept in metabolic cages to measure the faecal minerals excretion. There was no difference among the groups about serum iron values and parameters of red blood cells. The serum copper and zinc values were lower in the G2 and G3 on days 21 and 28 of the experiment, whereas the faecal copper, iron and zinc excretion was higher in the same groups. The superoxide dismutase (SOD) levels were lower in the G2 and G3 on day 28 whereas the levels of non-protein thiol groups (NPTH) showed a decrease on days 21 and 28. In relation to reactive species thio-barbituric acid (TBARS), there was an increase on day 28 in the G2 and G3. Based on these results, it was concluded that the oral supplementation with $200 \mathrm{mg}$ of iron, irrespective of its form, ferrous or ferric, does not increase the erythrocyte response in lambs. As well as, it has antagonist action on copper and zinc, reducing its serum concentrations and increasing the faecal excretion of these minerals. Moreover, the decrease of the serum copper and zinc concentrations causes a decrease in activity of superoxide dismutase, causing an oxidative stress situation.

Key words: Sheep, supplements, minerals, oxidative stress

\section{Introdução}

A ovinocultura é uma atividade de importância socioeconômica, sendo a produção de carne de cordeiro cada vez mais procurada, principalmente, pela crescente demanda de consumo, e lucratividade proporcionada (VIANA; SOUZA, 2007). Sendo assim, o uso de práticas de manejo como a suplementação mineral, se faz necessário para acarretar em aumento de produtividade no rebanho ovino (HENRY; MILES, 2000). Entretanto, o metabolismo dos minerais não pode ser considerado de maneira isolada, sendo a biodisponibilidade destes elementos influenciada pelas interações entre os mesmos (NOCEK; SOCHA; TOMLINSON, 2006). Estas interações podem ser de forma direta, quando ocorrem fenômenos competitivos durante a absorção intestinal ou utilização tecidual e, indiretas quando um mineral está envolvido no metabolismo do outro, de modo que a deficiência ou excesso de um acarreta no prejuízo da função do outro (BREMNER; BEATTIE, 1995).

Em ovinos jovens, os índices de morbidade e mortalidade são significativamente elevados em conseqüência de anemia desenvolvida durante os quadros de verminose gastrintestinais (KAWANO; YAMAMURA; RIBEIRO, 2001; MELLOR; STAFFORD, 2004). Nesse sentido, Rocha et al. (2007) afirmam que a suplementação de ferro em doses altas na forma injetável aumenta a resposta reticulocitária em cordeiros anêmicos, e de acordo com Ashmead (2001) a suplementação oral deste mineral em doses diárias ou doses altas intermitentes têm demonstrado um aumento na sua biodisponibilidade e consequentemente melhora na resposta eritropoiética em monogástricos. Segundo resultados de Hurtado, Claussen e Scott (1999), a suplementação semanal de ferro oral em indivíduos anêmicos leva a um aumento nos níveis de hemoglobina e volume corpuscular médio (VCM), indicando um aumento na resposta medular.

Porém, o ferro diminui a biodisponibilidade de cobre e zinco (ORTOLANI, 2002), que são componentes da enzima superóxido dismutase, responsável esta, pelo processo de detoxificação de radicais livres transformando dois ânions radicais superóxido em um peróxido de hidrogênio menos reativo que o anterior (AMES; SHINNENAGA; HAGEN, 1993). Além disto, também pode causar danos aos tecidos, se atuar como catalisador na conversão de peróxido de hidrogênio em radicais livres que atacam a membrana celular, proteínas e DNA (RIEGEL, 2002). Os resultados encontrados por Rocha et al. (2007), demonstram um aumento na peroxidação dos lipídios de membrana do eritrócito pela ação de espécies reativas ao ácido tiobarbitúrico (TBARS) em cordeiros suplementados com doses 
altas de ferro injetável. Resultados similares foram obtidos por Knutson, Walter e Ames (2000) através da aplicação de ferro oral em ratos. Nesse sentido, o presente estudo teve por objetivo avaliar o perfil oxidativo, eritrograma e interação mineral em cordeiros resilientes suplementados com diferentes formas de ferro oral.

\section{Material e Métodos}

Foram utilizados 27 cordeiros com idade entre 6 e 8 meses naturalmente infectados por parasitas gastrintestinais. Os animais no dia zero do experimento apresentaram volume globular entre 16 e 18\%. Foram formados três grupos; Grupo controle (GC) n=9, Grupo Sulfato ferroso (G2) $n=9$ e Grupo Sulfato férrico $(G 3) n=9$. Os animais do $\mathrm{G} 2$ receberam via oral diariamente durante 28 dias 1 grama de sulfato ferroso $\left(\mathrm{Fe}^{+2}\right)$, equivalente a 200 miligramas de ferro, os animais do G3 receberam 1 grama de sulfato férrico $\left(\mathrm{Fe}^{+3}\right)$ via oral diariamente durante 28 dias, também equivalente a 200 miligramas de ferro, enquanto que os animais do GC não receberam tratamento. Os animais foram mantidos em baias no sistema de cama sobreposta com água à vontade e a alimentação composta de feno de alfafa (Medicago sativa). A suplementação de ferro mais a concentração deste mineral na alfafa totalizaram um fornecimento de $800 \mathrm{ppm} /$ dia por cordeiro. Durante quatro dias, dois animais de cada grupo foram mantidos em gaiolas metabólicas para coleta de fezes com o objetivo de mensuração da excreção fecal de ferro, cobre e zinco. A contagem de ovos por grama de fezes, OPG, foi obtida individualmente pela técnica de Gordon e Whitlock (1939) nos dias 0, 7, 14, 21 e 28 do experimento. No dia zero também foi realizada cultura de fezes para a identificação de larvas (ROBERTS; O'SULLIVAN, 1950).

As coletas de sangue foram realizadas nos dias $0,7,14,21$ e 28 do experimento. As coletas foram feitas por meio da venopunção da jugular após anti-sepsia no local de punção. Avaliaram-se os níveis séricos de ferro através de kit comercial (Labtest, Belo Horizonte, MG, Brasil), enquanto que a avaliação de cobre e zinco plasmáticos foi realizada conforme a técnica descrita por Fick et al. (1980) e a mensuração de cobre, zinco e ferro fecal foi de acordo com a descrição de Tedesco et al. (1995). A lipoperoxidação da membrana do eritrócito foi avaliada pela mensuração das espécies reativas ao ácido tio-barbitúrico (TBARS), usando malondialdeído (MDA) para construção da curva padrão, de acordo com a técnica de Ohkawa, Ohishi e Yagi (1979).

A atividade da superóxido dismutase nos eritrócitos baseou-se na capacidade da enzima em inibir a auto-oxidação da epinefrina em pH alcalino, conforme Sun e Zigman (1978). A concentração dos grupos tióis não protéicos (NPTH) foi calculada usando uma curva padrão de glutationa reduzida, de acordo com Ellman (1959). As avaliações dos parâmetros das células vermelhas do sangue (volume globular, contagem de eritrócitos e concentração de hemoglobina) foram feitas através do método descrito por Jain (1986).

A estatística constou de uma análise de variância (ANOVA), sendo a comparação entre as médias feita pelo teste de Tukey. Os cálculos foram processados no programa "Graphpad Instat".

\section{Resultados e Discussão}

Não houve diferença entre os grupos na mensuração de ferro sérico em nenhum momento experimental (Tabela 1) ( $\mathrm{P}>0,05)$, apesar dos níveis de suplementação neste experimento ser mais altos que a recomendação diária para a espécie (NRC, 2001). Isto pode ser explicado devido ao mecanismo de homeostasia deste mineral, onde a absorção duodenal e a excreção fecal são reguladas pela necessidade do organismo em relação ao ferro (OATS, 2007). Também não houve diferença nos valores de volume globular, contagem de eritrócitos e concentração de hemoglobina $(P>0,05)$, independente da forma de administração 
de ferro, ferrosa ou férrica, demonstrando que não ocorreu um efeito suprafisiológico no eritrograma. A avaliação dos valores de OPG nos três grupos durante o período experimental demonstrou a presença de parasitismo (Tabela 1), entretanto, a suplementação de ferro em nenhuma das formas,
G2 e G3, melhorou a resposta eritropoiética frente ao desafio da verminose (Tabela 2). O resultado da cultura de fezes e identificação de larvas demonstrou a presença de parasitas do gênero Haemonchus sp (85\%), Trichostrongylus sp. (7\%), Cooperia sp. (5\%) e Ostertagia sp. (3\%).

Tabela 1. Valores de OPG (ovos por grama de fezes) em cordeiros suplementados com ferro oral na forma ferrosa (G2), forma férrica (G3) e grupo controle (GC) em cada momento experimental.

\begin{tabular}{lccccc}
\hline & Dia 0 & Dia 7 & Dia 14 & Dia 21 & Dia 28 \\
\hline GC & $3350 \pm 1380^{\mathrm{a}}$ & $3990 \pm 1225^{\mathrm{a}}$ & $4230 \pm 1255^{\mathrm{a}}$ & $4050 \pm 1260^{\mathrm{a}}$ & $3850 \pm 1310^{\mathrm{a}}$ \\
G2 & $4260 \pm 1187^{\mathrm{a}}$ & $3650 \pm 1070^{\mathrm{a}}$ & $7150 \pm 1330^{\mathrm{a}}$ & $4150 \pm 1300^{\mathrm{a}}$ & $4350 \pm 1460^{\mathrm{a}}$ \\
G3 & $4150 \pm 1100^{\mathrm{a}}$ & $3850 \pm 1375^{\mathrm{a}}$ & $4450 \pm 1045^{\mathrm{a}}$ & $3790 \pm 1255^{\mathrm{a}}$ & $3900 \pm 1395^{\mathrm{a}}$ \\
\hline
\end{tabular}

${ }^{a} \mathrm{P}>0,05=$ não houve diferença entre grupos nos valores de $\mathrm{OPG}$ em nenhum momento experimental.

Fonte: Elaboração dos autores.

Segundo Van Der A et al. (2005), o ferro dietético apresenta-se em duas formas, heme e não-heme ou inorgânica. Embora a forma hêmica $\left(\mathrm{Fe}^{+2}\right)$ seja mais biodisponível, a forma inorgânica $\left(\mathrm{Fe}^{+3}\right)$ está presente em maior concentração na dieta. Para que o ferro na forma férrica seja absorvido pela membrana apical do enterócito, ele precisa ser oxidado a forma ferrosa pela citocromo b duodenal ferroredutase (Dcytb) (ANDERSON et al., 2007). Após este processo, o ferro é transportado pela membrana apical através de um transportador de metal divalente 1 (DMT1), que além deste mineral também transporta outros prótons como cobre, zinco e manganês (DUNN; RAHMANTO; RICHARDSON, 2006), sendo esta uma das causas do antagonismo entre estes minerais. Além deste fator, no caso do zinco existe o antagonismo pela mobiliferrina, proteína responsável pelo transporte intracelular de ferro, zinco, cobalto e chumbo, causando competição pela absorção entre eles (CHASTON et al., 2008). Em relação ao cobre, acredita-se que o sulfato presente no rúmen também tenha papel de antagonista ao se ligar ao ferro formando um complexo insolúvel de sulfato de ferro (FeS). Este complexo no $\mathrm{pH}$ ácido do abomaso é dissociado e o sulfato se liga ao cobre formando um complexo insolúvel de sulfato de cobre $(\mathrm{CuS})$, tornando o cobre indisponível para absorção (SUTTLE, 1991). O excesso de ferro na dieta aumentou a excreção fecal do próprio ferro, do cobre e do zinco nos grupos G2 (ferrosa) e G3 (férrica) em relação ao $\mathrm{GC}$ (controle) $(\mathrm{P}<0,05)$ (Figuras $1 \mathrm{~A} / \mathrm{B}$ ). $\mathrm{O}$ antagonismo entre estes minerais explica a diminuição dos valores de cobre e zinco plasmático nos dias $21(\mathrm{P}<0,05)$ e $28(\mathrm{P}<0,05)$ do experimento nos grupos G2 e G3 em relação ao GC (Tabela 2). Esta redução nos teores séricos de cobre e zinco pode ser responsável pelo hábito de tricofagia e despigmentação da lã no G2 e G3. Tanto o cobre como o zinco são co-fatores da superóxido dismutase. Esta enzima participa no processo de detoxificação de radicais livres transformando dois ânions radicais superóxidos em um peróxido de hidrogênio menos reativo que o anterior (AMES; SHINNENAGA; HAGEN, 1993). 
Tabela 2. Média \pm desvio padrão de Eritrócitos, Volume globular (VG), Hemoglobina ( $\mathrm{Hb}$ ), Ferro Sérico (Fe), Cobre plasmático $(\mathrm{Cu})$, Zinco plasmático $(\mathrm{Zn})$ em cordeiros suplementados com ferro oral na forma ferrosa (G2), forma férrica (G3) e grupo controle (GC) em cada momento experimental.

\begin{tabular}{|c|c|c|c|c|c|c|c|}
\hline & & $\begin{array}{l}\text { VG } \\
(\%)\end{array}$ & $\begin{array}{l}\text { Eritrócitos } \\
\left(\mathrm{n}^{\circ} \mathrm{x} 10^{6} \mu \mathrm{L}\right)\end{array}$ & $\begin{array}{l}\text { Hemoglobina } \\
(\mathrm{g} / \mathrm{dl})\end{array}$ & $\begin{array}{c}\mathrm{Fe}^{+2} \\
(\mu \mathrm{g} / \mathrm{dl})\end{array}$ & $\begin{array}{c}\mathrm{Cu}^{+1} \\
(\mu \mathrm{mol} / \mathrm{L})\end{array}$ & $\begin{array}{c}\mathrm{Zn} \\
(\mu \mathrm{g} / \mathrm{dl})\end{array}$ \\
\hline \multirow{3}{*}{ Dia 0} & $\mathrm{GC}$ & $16,0 \pm 1,2^{\mathrm{a}}$ & $4,2 \pm 0,7^{a}$ & $5,0 \pm 0,2^{\mathrm{a}}$ & $171,1 \pm 12,0^{\mathrm{a}}$ & $8,3 \pm 0,8^{\mathrm{a}}$ & $32,1 \pm 1,7^{\mathrm{a}}$ \\
\hline & G2 & $15,6 \pm 0,8^{\mathrm{a}}$ & $3,9 \pm 1,1^{\mathrm{a}}$ & $5,2 \pm 0,8^{\mathrm{a}}$ & $183,8 \pm 8,0^{\mathrm{a}}$ & $8,3 \pm 1,6^{\mathrm{a}}$ & $27,4 \pm 0,9^{\mathrm{a}}$ \\
\hline & G3 & $16,1 \pm 1,1^{\mathrm{a}}$ & $4,0 \pm 0,4^{\mathrm{a}}$ & $5,5 \pm 1,1^{\mathrm{a}}$ & $176,3 \pm 11,2^{\mathrm{a}}$ & $8,9 \pm 0,8^{a}$ & $29,9 \pm 1,1^{\mathrm{a}}$ \\
\hline \multirow{3}{*}{ Dia 7} & $\mathrm{GC}$ & $16,2 \pm 0,9^{\mathrm{a}}$ & $4,3 \pm 0,5^{\mathrm{a}}$ & $5,8 \pm 0,7^{\mathrm{a}}$ & $217,6 \pm 7,6^{\mathrm{a}}$ & $9,7 \pm 1,5^{\mathrm{a}}$ & $34,4 \pm 0,6^{\mathrm{a}}$ \\
\hline & G2 & $15,8 \pm 0,6^{\mathrm{a}}$ & $4,1 \pm 1,2^{\mathrm{a}}$ & $5,9 \pm 1,3^{\mathrm{a}}$ & $195 \pm 12,3^{\mathrm{a}}$ & $8,3 \pm 0,6^{\mathrm{a}}$ & $27,2 \pm 0,4^{\mathrm{a}}$ \\
\hline & G3 & $17,0 \pm 1,0^{\mathrm{a}}$ & $4,4 \pm 1,4^{\mathrm{a}}$ & $5,7 \pm 0,8^{a}$ & $198,1 \pm 8,0^{\mathrm{a}}$ & $9,1 \pm 1,4^{\mathrm{a}}$ & $29,4 \pm 1,3^{\mathrm{a}}$ \\
\hline \multirow{3}{*}{ Dia 14} & $\mathrm{GC}$ & $16,2 \pm 0,8^{\mathrm{a}}$ & $4,1 \pm 1,3^{\mathrm{a}}$ & $5,7 \pm 1,2^{\mathrm{a}}$ & $203,2 \pm 11,9^{a}$ & $9,6 \pm 0,9^{\mathrm{a}}$ & $32,0 \pm 1,5^{\mathrm{a}}$ \\
\hline & G2 & $16,4 \pm 1,3^{\mathrm{a}}$ & $4,7 \pm 0,9^{\mathrm{a}}$ & $5,6 \pm 0,8^{a}$ & $207,6 \pm 7,5^{\mathrm{a}}$ & $8,6 \pm 1,3^{a}$ & $26,8 \pm 0,7^{\mathrm{a}}$ \\
\hline & G3 & $17,2 \pm 0,7^{\mathrm{a}}$ & $4,5 \pm 1,2^{\mathrm{a}}$ & $6,0 \pm 0,4^{a}$ & $201 \pm 11,1^{\mathrm{a}}$ & $8,5 \pm 0,7^{a}$ & $27,6 \pm 1,3^{\mathrm{a}}$ \\
\hline \multirow{3}{*}{ Dia 21} & $\mathrm{GC}$ & $18,1 \pm 1,1^{\mathrm{a}}$ & $4,7 \pm 1,6^{\mathrm{a}}$ & $6,0 \pm 1,1^{\mathrm{a}}$ & $206,7 \pm 9,0^{\mathrm{a}}$ & $9,8 \pm 1,4^{\mathrm{a}}$ & $32,8 \pm 0,8^{a}$ \\
\hline & $\mathrm{G} 2$ & $19,0 \pm 0,9^{\mathrm{a}}$ & $4,6 \pm 0,7^{\mathrm{a}}$ & $6,3 \pm 0,6^{a}$ & $209 \pm 13,4^{\mathrm{a}}$ & $7,6 \pm 0,6^{b}$ & $23,9 \pm 1,2^{b}$ \\
\hline & G3 & $19,3 \pm 1,4^{\mathrm{a}}$ & $5,0 \pm 1,3^{\mathrm{a}}$ & $6,4 \pm 0,3^{a}$ & $203,6 \pm 11,7^{\mathrm{a}}$ & $7,4 \pm 1,3^{b}$ & $22,3 \pm 1,4^{b}$ \\
\hline \multirow{3}{*}{ Dia 28} & $\mathrm{GC}$ & $21,0 \pm 0,7^{\mathrm{a}}$ & $5,1 \pm 1,1^{\mathrm{a}}$ & $7,5 \pm 0,5^{\mathrm{a}}$ & $210,1 \pm 8,9^{\mathrm{a}}$ & $9,4 \pm 0,8^{\mathrm{a}}$ & $32,6 \pm 0,9^{\mathrm{a}}$ \\
\hline & $\mathrm{G} 2$ & $22,3 \pm 1,5^{\mathrm{a}}$ & $4,9 \pm 0,8^{\mathrm{a}}$ & $7,0 \pm 1,3^{\mathrm{a}}$ & $199,8 \pm 13,7^{\mathrm{a}}$ & $7,2 \pm 1,6^{b}$ & $21,4 \pm 0,8^{b}$ \\
\hline & G3 & $20,0 \pm 0,5^{\mathrm{a}}$ & $5,3 \pm 1,4^{\mathrm{a}}$ & $6,8 \pm 0,2^{\mathrm{a}}$ & $205,4 \pm 8,4^{\mathrm{a}}$ & $6,9 \pm 0,9^{b}$ & $20,0 \pm 1,5^{\mathrm{b}}$ \\
\hline
\end{tabular}

${ }^{\mathrm{ab}}$ Letras coincidentes indicam diferença estatística entre os grupos.

Fonte: Elaboração dos autores.

Devido à diminuição dos valores de cobre e zinco plasmático nos dias 21 e 28, houve também no dia 28 do experimento uma redução na atividade da superóxido dismutase (Tabela 3) $(\mathrm{P}<0,05)$, com conseqüente aumento na concentração das espécies reativas ao ácido tiobarbitúrico (TBARS) nos grupos G2 e G3, (Tabela 3) $(\mathrm{P}<0,05)$ em relação ao grupo GC, o que indica uma situação de estresse oxidativo (DRÖGE, 2002) devido à diminuição da atividade de enzimas antioxidantes, neste caso, da superóxido dismutase. Os valores dos grupamentos tióis (NPTH) diminuíram significativamente nos grupos G2 e G3 nos dias 21 e 28 do experimento $(\mathrm{P}<0,05)$ (Tabela 3), em relação ao GC, provavelmente, ocasionado pela redução da atividade da superóxido dismutase, indicando um aumento na oxidação da enzima glutationa peroxidase com o objetivo de neutralizar as espécies reativas ao ácido tiobarbitúrico (JUNIOR et al., 2001). Os resultados obtidos por Imai et al. (1991), demonstram que geralmente ocorre aumento nos valores de TBARS e diminuição nos valores de NPTH em situações de estresse oxidativo.

De acordo com os resultados obtidos, concluise que a suplementação de $200 \mathrm{mg}$ de ferro, independente da sua forma, ferrosa ou férrica, não aumenta a resposta eritrocitária em cordeiros. Bem como, tem ação antagonista sobre cobre e zinco, diminuindo suas concentrações séricas e aumentando a excreção fecal destes minerais. Além disso, pela diminuição das concentrações séricas de cobre e zinco causa uma diminuição da atividade da superóxido dismutase, ocasionando uma situação de estresse oxidativo. 
Tabela 3. Média \pm desvio padrão de Grupamentos Tióis não protéicos (NPTH), Superóxido Dismutase (SOD) e Espécies Reativas ao Ácido Tiobarbitúrico (TBARS) em cordeiros suplementados com ferro oral na forma ferrosa $(\mathrm{G} 2)$, forma férrica (G3) e grupo controle (GC) em cada momento experimental.

\begin{tabular}{|c|c|c|c|c|}
\hline & & $\begin{array}{c}\text { TBARS } \\
\text { (nmol MDA/g Hb) }\end{array}$ & $\begin{array}{c}\text { SOD } \\
\text { (UI/g Hb) }\end{array}$ & $\begin{array}{c}\text { NPTH } \\
\text { (nmol/L sg total) }\end{array}$ \\
\hline \multirow{3}{*}{ Dia 0} & GC & $2,4 \pm 0,3^{\mathrm{a}}$ & $0,38 \pm 0,03^{\mathrm{a}}$ & $1,64 \pm 0,02^{\mathrm{a}}$ \\
\hline & $\mathrm{G} 2$ & $2,6 \pm 0,4^{\mathrm{a}}$ & $0,35 \pm 0,06^{\mathrm{a}}$ & $1,75 \pm 0,04^{\mathrm{a}}$ \\
\hline & G3 & $2,4 \pm 0,6^{\mathrm{a}}$ & $0,40 \pm 0,02^{\mathrm{a}}$ & $1,45 \pm 0,03^{\mathrm{a}}$ \\
\hline \multirow{3}{*}{ Dia 7} & GC & $2,1 \pm 0,4^{\mathrm{a}}$ & $0,34 \pm 0,03^{\mathrm{a}}$ & $1,74 \pm 0,04^{\mathrm{a}}$ \\
\hline & G2 & $2,2 \pm 0,3^{\mathrm{a}}$ & $0,36 \pm 0,04^{\mathrm{a}}$ & $1,68 \pm 0,03^{\mathrm{a}}$ \\
\hline & G3 & $2,4 \pm 0,3^{a}$ & $0,36 \pm 0,05^{\mathrm{a}}$ & $1,46 \pm 0,05^{\mathrm{a}}$ \\
\hline \multirow{3}{*}{ Dia 14} & GC & $2,0 \pm 0,5^{\mathrm{a}}$ & $0,35 \pm 0,06^{\mathrm{a}}$ & $1,67 \pm 0,03^{\mathrm{a}}$ \\
\hline & G2 & $2,3 \pm 0,3^{\mathrm{a}}$ & $0,34 \pm 0,03^{\mathrm{a}}$ & $1,56 \pm 0,06^{\mathrm{a}}$ \\
\hline & G3 & $2,1 \pm 0,6^{\mathrm{a}}$ & $0,31 \pm 0,02^{\mathrm{a}}$ & $1,58 \pm 0,05^{\mathrm{a}}$ \\
\hline \multirow{3}{*}{ Dia 21} & $\mathrm{GC}$ & $1,9 \pm 0,4^{\mathrm{a}}$ & $0,34 \pm 0,03^{\mathrm{a}}$ & $1,63 \pm 0,03^{\mathrm{a}}$ \\
\hline & $\mathrm{G} 2$ & $2,1 \pm 0,2^{\mathrm{a}}$ & $0,31 \pm 0,02^{\mathrm{a}}$ & $1,1 \pm 0,02^{\mathrm{b}}$ \\
\hline & G3 & $2,2 \pm 0,4^{\mathrm{a}}$ & $0,32 \pm 0,04^{\mathrm{a}}$ & $0,9 \pm 0,07^{\mathrm{b}}$ \\
\hline \multirow{3}{*}{ Dia 28} & $\mathrm{GC}$ & $2,1 \pm 0,3^{\mathrm{a}}$ & $0,34 \pm 0,06^{\mathrm{a}}$ & $1,66 \pm 0,03^{\mathrm{a}}$ \\
\hline & $\mathrm{G} 2$ & $3,6 \pm 0,4^{b}$ & $0,21 \pm 0,04^{\mathrm{b}}$ & $1,0 \pm 0,05^{\mathrm{b}}$ \\
\hline & G3 & $3,4 \pm 0,3^{\mathrm{b}}$ & $0,19 \pm 0,06^{\mathrm{b}}$ & $0,9 \pm 0,04^{b}$ \\
\hline
\end{tabular}

ab Letras diferentes indicam diferença estatística entre os grupos.

Fonte: Elaboração dos autores.

Figuras $1 \mathbf{A} / \mathbf{B}$. Excreção fecal de ferro em cordeiros suplementados com ferro oral na forma ferrosa (G2), forma férrica (G3) e grupo controle (GC) mantidos em gaiola metabólica. 1B) Excreção fecal de zinco e cobre em cordeiros suplementados com ferro oral na forma ferrosa (G2), forma férrica (G3) e grupo controle (GC) mantidos em gaiola metabólica.

Figura 1A

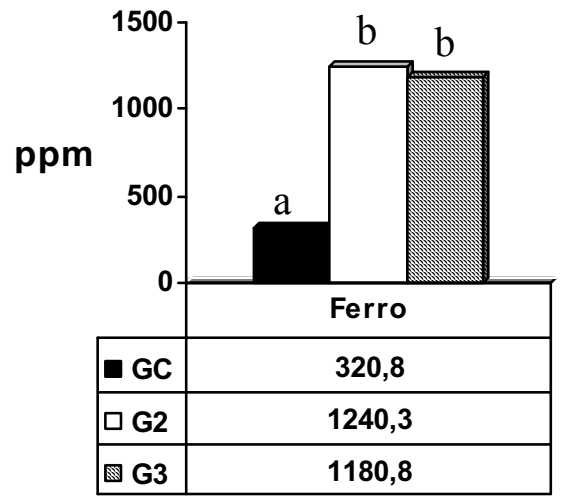

Figura 1B

GC $\square$ G2 $\square$ G3

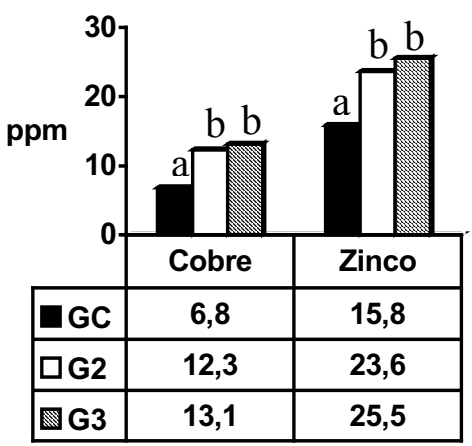

${ }^{\mathrm{ab}}$ Letras diferentes indicam diferença estatística entre os grupos.

Fonte: Elaboração dos autores. 


\section{Comitê de Ética e Biossegurança}

Aprovado pelo Comitê de Ética em Experimentação Animal da UFSM: número 26/2008.

\section{Referências}

AMES, B. N.; SHINNENAGA, M. K.; HAGEN, T. M. Oxidants, antioxidants and the degenerative diseases of aging. Procedure National Academic Science, Washington, EUA, v. 90, n. 17, p. 7915-7922, 1993.

ANDERSON, G. J.; DARSHAN, D.; SARAH, J. W.; DAVID, M. F. Regulation of systemic iron homestasic: how the body response to changes in iron demands. Biometals, Brisbane, v. 20, n. 3-4, p. 665-674, 2007.

ASHMEAD, H. D. The chemistry of ferrous bisglycinate chelate. Archives Latinoamerican Nutrition, Reino Unido, v. 51 n. 1, p. 13-21, 2001.

BREMNER, I.; BEATTIE, J. H. Copper and zinc metabolism in health and disease: speciation and interactions. Proceedings Nutritional Society, Reino Unido, v. 54, n.2, p. 489-499, 1995.

CHASTON, T.; CHUNG, B.; MASCARENHAS, M.; MARKS, J.; PATEL, B.; SRAI, S. K.; SHARP, P. Evidence for differential effects of hepcidin in macrophages and intestinal epithelial cells. GUT, Reino Unido, v. 57, n. 3, p. 374-382, 2008.

DRÖGE, W. Free radicals in the physiological control of cell function. Physiological Reviews, Bethesda, EUA, v. 82, n. 1, p. 47-95, 2002.

DUNN, L. L.; RAHMANTO, Y. S.; RICHARDSON, D. R. Iron uptake and metabolism in the new millennium. Trends in Cell Biology, Sydney, v. 17, n. 2, p. 93-100, 2006.

ELLMAN, G. L. Tissue sulfhydryl groups. Archives Biochemistry Biophysics, v. 82, p. 70-77, 1959.

FICK, K. R.; McDOWELL, L. R.; MILES, P. H.; WILKINSON, N. S.; FUNK, J. D.; CONRAD, J. H. Métodos de análises de minerais em tecidos de animais e de plantas. 2. ed. Flórida: Universidade da Flórida, 1980.

GORDON, H. H.; WHITLOCK, H. V. A new technique for counting nematode eggs in sheep faeces. Journal Council Scientific Industry Research, Austrália, v. 12, p. 50-52, 1939.

HENRY, P. R.; MILES, R. D. Interactions among the trace minerals. Ciência Animal Brasiliera, Goiânia, Goiás, v. 1, n. 2, p. 95, 2000.
JUNIOR, L. R.; HÖER, N. F.; VELLASCO, A. P.; KUBOTA, L. T. Sistema antioxidante envolvendo o ciclo metabólico da glutationa associado a métodos eletroanalíticos na avaliação do estresse oxidativo. Química Nova, São Paulo, v. 24, n. 1, p. 112-119, 2001.

HURTADO, E. K.; CLAUSSEN, A. H.; SCOTT, K. G. Early childhood anemia and mild or moderate mental retardation. American Journal Clinical Nutrition, Bethesda, EUA, v. 69, n. 1, p. 115-119, 1999.

IMAI, K.; AIMOTO, T.; SATO, M.; KIMURA, R. Antioxidative effect of protoporphyrin on lipid peroxidation in tissues homogenates of intravenously administrated rats. Journal Pharmacobio Dynamics, Osaka, v. 14, n. 1, p. 20-24, 1991.

JAIN, N. C. Schalm's veterinary hematology. 4. ed. Philadelphia: Lea \& Febiger, 1986. 1221 p.

KAWANO, E. L.; YAMAMURA, M. H.; RIBEIRO, E. L. A. Efeitos do tratamento com anti-helmíntico em cordeiros naturalmente infectados com helmintos gastrintestinais sobre os parâmetros hematológicos, ganho de peso e qualidade da carcaça. Arquivos da Faculdade de Veterinária, UFRGS, Porto Alegre, v. 29, n. 2, p. 113-121, 2001.

KNUTSON, M. D.; WALTER, P. B.; AMES, B. Both iron deficiency and daily iron supplements increase lipid peroxidations in rats. Journal of Nutrition, Bethesda, USA, v. 130, n. 3, p. 621-628, 2000.

MELLOR, D. J.; STAFFORD, K. J. Animal welfare implications of neonatal mortality and morbidity in farm animals. The Veterinary Journal, Londres, v. 168, n. 2, p. 118-133, 2004.

NOCEK, J. E.; SOCHA, M. T.; TOMLINSON, D. J. The effect of trace mineral fortification level and source on performance of dairy cattle. Journal Dairy Science, California, v. 89, n. 7, p. 2679-2693, 2006.

NATIONAL RESEARCH COUNCIL - NRC. Nutrient requirements of dairy cattle. $7^{\text {th }}$ ed. Washington D.C.: Ed. National Academy Press, 2001. 381 p.

OATS, P. S. The role of hepcidin and ferroportin in iron absorption. Histology and Histopathology, Nedlands, v. 22, n. 7, p.791-804, 2007.

OHKAWA, H.; OHISHI, N.; YAGI, K. Assay for lipid peroxides in animal tissues by thiobarbituric acid reaction. Analytical Biochemestry, Nagoya, v. 95, n. 2, p. 351-358, 1979.

ORTOLANI, E. L. Macro e microelementos. In: SPINOSA, H. S.; GÓRNIAK, S. L.; BERNARDI, M. M. Farmacologia aplicada à medicina veterinária. 3. ed. São Paulo: Guanabara Koogan S. A., 2002. p. 641-651. 
RIEGEL R. E. Radicais livres. In: 3. ed. São Leopoldo: Unisinos, 2002, p. 507-536.

ROBERTS, F. H. S.; O'SULLIVAN, P. J. Methods for eggs counts and larval cultures for strongyles infecting the gastrointestinal tract of catlle. Australian Journal Agriculture Research, Austrália, v. 1, n. 1, p. 99-102, 1950.

ROCHA, R. X.; BONDAN, C.; MARINHO, R.; LOPES, S. T. A.; CECIM, M. Dextran iron in anemic lambs: effects on reticulocytosis and free radical production. Ciência Rural, Santa Maria, v. 37, n. 5, p. 1344-1348, 2007.

SUN, M.; ZIGMAN, S. An improved spectrophotometric assay for superoxide dismutase based on epinephrine autoxidation. Analytical Biochemistry, New York, v. 90, n. 1, p. 81-89, 1978.
SUTTLE, N. F. The interactions between copper, molybdenum, and sulphur in ruminant nutrition. Annual Veterinary Nutrition, v. 11, p. 121-140, 1991.

TEDESCO, M. J.; GIANELLO, C.; BISSANI, C. A.; BOHNEN, H.; VOLKWEISS, S. J. Análise de solo, plantas e outros materiais. 2. ed. Porto Alegre: UFRGS, 1995, p. 98-105.

VAN DER A, D. L.; PEETERS, P. H. M.; GROBBEE, D. E.; MARX, J. J. M.; VAN DER SCHOUW, Y. Dietary haem iron and coronary heart disease in women. European Heart Journal, Utrecht, v. 26, p. 257-262, 2005.

VIANA, J. G. A.; SOUZA, R. S. Comportamento dos preços dos produtos derivados da ovinocultura no Rio Grande do Sul no período de 1973 a 2005. Ciência e Agrotecnologia, Lavras, v. 31, n. 1, p. 191-199, 2007. 